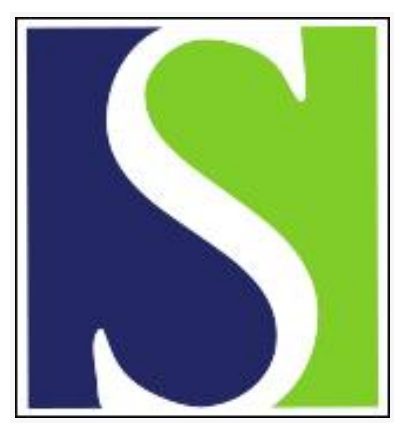

Scand J Work Environ Health 1983;9(2):189-193

https://doi.org/10.5271/sjweh.2427

Issue date: Apr 1983

Some aspects of strategies and solutions in accident prevention.

by Hakkinen $\mathrm{K}$

This article in PubMed: www.ncbi.nlm.nih.gov/pubmed/6648416

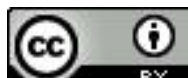




\title{
Some aspects of strategies and solutions in accident prevention
}

\author{
by Kari Häkkinen, $M S c(E n g)^{1}$
}

\begin{abstract}
HÄKKINEN K. Some aspects of strategies and solutions in accident prevention. Scand $j$ work environ health 9 (1983) 189-193. Accident prevention measures are traditionally classified into technical, organizational and behavioral solutions. A review of some commonly used strategies for accident prevention illustrates some discrepancies between different approaches and the need to develop more comprehensive strategies. Several factors, including protective efficiency and disadvantages at work, must be taken into account when the solutions are evaluated. Some solutions to prevent load disengagement from cranes were evaluated. Measurements of the pressing force showed that the efficiency of the safety latch of a clamp for plate lifting is inadequate to provide protection under all exceptional lifting conditions and in all situations for which the safety latch is intended. The delay caused by the attachment of a lifting hook equipped with a safety latch was measured. The handling of some of the most reliable and technically safe latches requires additional operations and thereby limits their practical application.
\end{abstract}

Key terms: behavioral solutions, cranes, organizational solutions, technical solutions.

Accident research deals with the processes, events, and characteristics of a particular system so that the causal relationships leading to accidents can be detected. The main objectives of accident research are to prevent accidents and to reduce their frequency and severity.

Today there are various methods for detecting factors leading to accidents and for analyzing hazards at the workplace. However preventive solutions are often presented intuitively without the systematic consideration of different types of solutions. Measures such as the installation of machine guards, the use of personal protectors, and training and promotional campaigns are carried out at workplaces and are required by standards, without any evaluation beforehand or afterwards. Too often the solutions are later found to be ineffective, uneconomical, uncomfortable, and removed from the point of danger. The need for studies within this

1 Department of Occupational Safety, Institute of Occupational Health, Helsinki, Finland.

Reprint requests to: $\mathrm{Mr}$ K Häkkinen, Institute of Occupational Health, Laajaniityntie 1, SF01620 Vantaa, Finland. area has been emphasized by many researchers $(10,13,15,18)$.

The solutions to accident prevention may be divided into the following three main categories $(13,17)$ : technical measures, organizational measures, and behavioral measures.

Primary technical solutions are those which, by design, are intrinsically safe without any additional safety features. This foremost requirement should be remembered as the general goal of efforts to attain safety, but additional technical solutions and other measures are also needed.

The importance of organizational measures should also be stressed. The solutions are often excellently presented in standards and handbooks. Unfortunately they do not function or are not available at workplaces. The time span between the development of a solution and its practical application is often too long.

Behavioral measures include training, instruction, and safety rules. The use of personal protective equipment may also be considered a behavioral measure because of its great subjective influence. 
Various alternative methods should overlap well, and they should complement one another. Frequently more than one solution is required, eg, education and training about new safety rules or new types of safety equipment.

The solutions should meet certain requirements. Some of the basic presuppositions are (1): (i) the effect should be widespread, ie, the solution should be as effective as possible in preventing accidents; (ii) the solution should be permanent or at least intended for long-term efficiency; (ii) the solution should not create new risks; (iv) the solution should not disturb normal routine: (v) the cost should be moderate in relation to the output expected; (vi) the measure should be easy to implement immediately (If the implemention takes time, it should be complemented by other arrangements with immediate effects); (vii) the measure should prevent the accident, not just the injury.

\section{Strategies of prevention}

The concepts hazard and energy are commonly combined. It is generally believed that the more energy present at a workplace, the greater the accident potential. Many authors have proposed various modifications of relationships between energy and accident risk (3, 4, 6, 8,11 ).

A strategy of safety modified from that of Firenze (6) is presented in fig 1. Accidents may be prevented by affecting the source, the path, or the object of the energy involved. In the figure situation 0 describes the hazardous conditions that should be prevented. In 1 the energy is in a nonhazardous form. In 2 the worker has been replaced by automation or remote

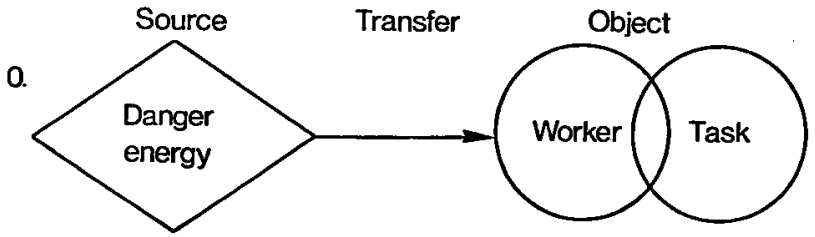

1.

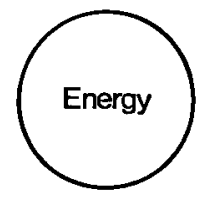

2.

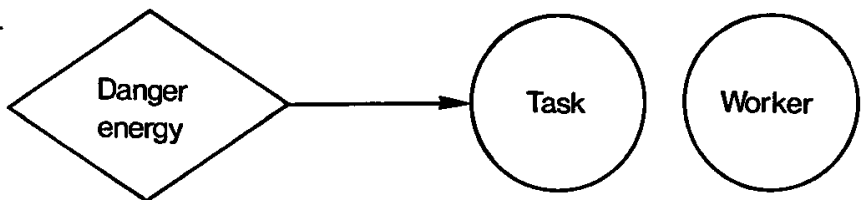

3.

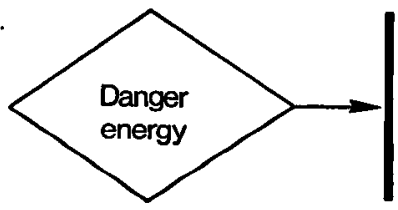

4.

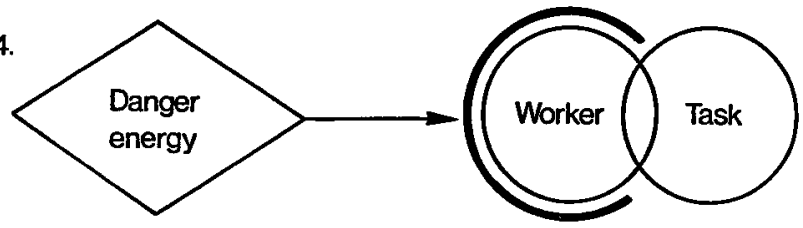

Fig 1. The energy approach of solutions according to Firenze (6). ( $0=$ free energy transfer, dangerous situation, $1=$ nonhazardous form of energy, $2=$ worker replacement, $3=$ setting of a physical barrier, $4=$ the use of personal protectors. 
control. The next possibility, number 3 , is to construct a physical barrier between the energy and the worker. The final solution, number 4 , is the use of personal protectors.

The analysis of energy is often a valuable procedure for revealing accident potential. Many accidents resulting from the release of energy and its contact with the human body actually occur. But problems may arise, especially when attempts are made to define acceptable energy limits (eg, in solution type 1).

Under certain conditions energy which is not usually hazardous may cause serious injury. The human tolerance of different energies varies widely according to the body part, and the probable point of contact is often difficult to anticipate. Both the energy and the tolerance values are, to a great extent, approximations (7, 16).

Often the energy does not come from outside; rather it is associated with human movement. Accidents due to slips and falls are not predictable with the analysis of energy.

Frequently the analysis of energy does not reveal the errors and mishaps starting an accident chain - the very points at which prevention is often the most effective. In any case, energy analysis has been reported to be useful in practice when risk of serious injury is being studied and when it is combined with other information, eg, the analysis of unroutine operations and aspects of human error (14).

Another strategy is to analyze the possible chain of events leading to accidents and to disconnect the chain (fig 2). The main precondition is precise knowledge of all the relevant events in the chain based on the occurrence of previous accidents or on the imagining of the events that might occur. Again problems may arise. For example something may be omitted, or perhaps all the possible events in the chain are not known. Techniques dealing with chains of events have been discussed in some publications $(5,12)$.

It has been rather usual to separate pedestrians and car traffic by the construction of bridges so that pedestrians can cross streets safely. In practice many of these bridges are not safe solutions because people do not use them. The access to the bridge causes the expenditure of extra time and energy. Very similar situations occur quite frequently also at workplaces; a technically safe solution is not safe in practice because people do not behave the way the designer thought they would or rather, the designer is not aware of man's natural behavior under the particular circumstances in question.

Based on several studies and practical experience, Burkardt (2) analyzed behavioral strategies. When safe behavior causes trouble, a change occurs in the unsafe direction. Safe behavior can be promoted if the negative results of unsafe behavior are increased or if the safe manner of working is made easier and more positive.

\section{Evaluation of solutions to prevent load detachment}

One study (9) has examined the safety latches of clamps for plate lifting. The clamps are usually equipped with a spring-operated safety mechanism that produces a pressing force. The force should be high enough to hold the plate firmly during moments when tension due to the

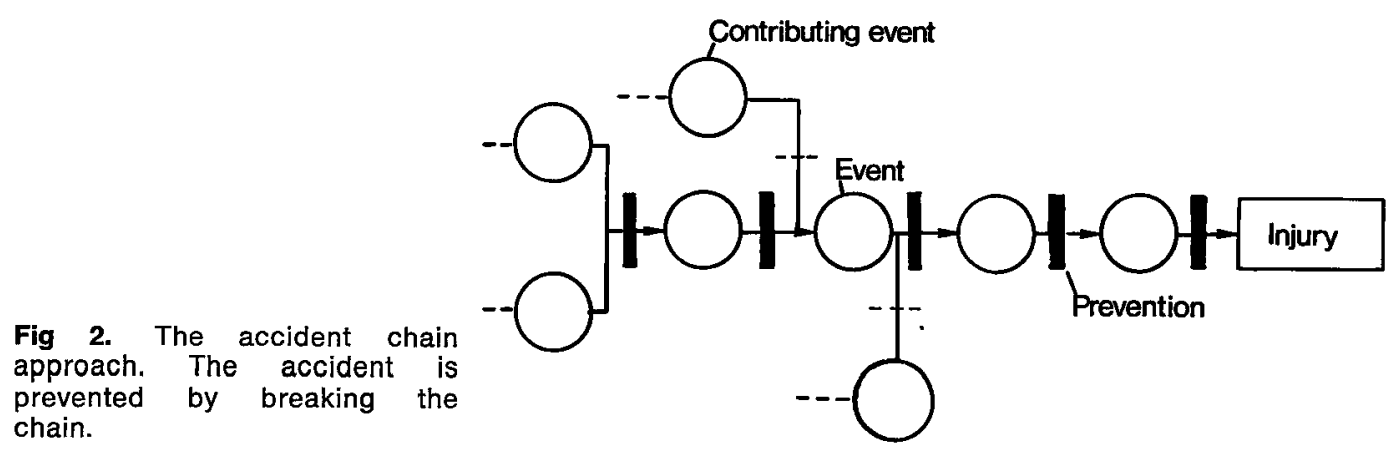


load is released temporarily, eg, when the load rests partly on the ground.

The prepressing forces of the locks ranged from only 1 to $6 \%$ of the rated capacity of the clamps. The tests were completed by loading the clamps with only a lateral force. A lateral force of $3 \%$ of the rated capacity was enough to start
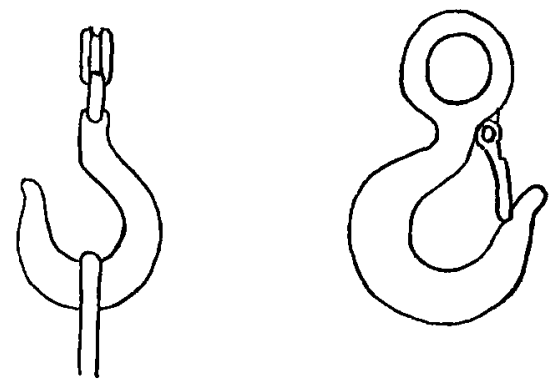

FASTENING $2.1 \mathrm{~s}$ FAstening $3.0 \mathrm{~s}$ UNFASTENING $2.0 \mathrm{~s}$ UNFASTENING $3.1 \mathrm{~s}$
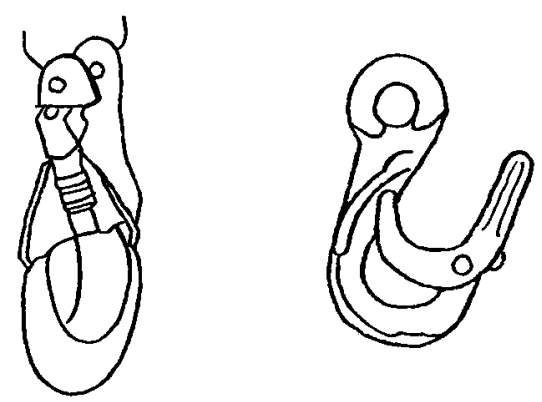

FASTENING $7.4 \mathrm{~s}$ FASTENING $13.8 \mathrm{~s}$ UNFASTENING $5.1 \mathrm{~s}$ UNFASTENING $10.9 \mathrm{~s}$
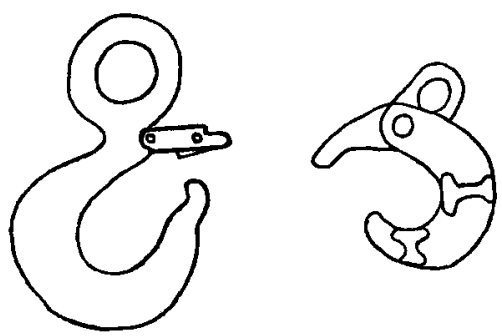

\section{FASTENING $10.5 \mathrm{~s}$ FASTENING $7.7 \mathrm{~s}$ UNFASTENING $7.4 \mathrm{~s}$ UNFASTENING $5.8 \mathrm{~s}$}

Fig 3. The average fastening and unfastening times registered for six hooks. (Number of measurements $=35$ ) slippage of the plate when the prepressing force alone secured the attachment. The study indicated that the protective effect of the lock was not good enough for safe plate gripping in all the situations it is intended for and that the influence is generally overestimated by manufacturers and users.

Another study presently in progress concerns safety latches of lifting hooks. The purpose of this mechanism is to prevent accidents by reducing the possibility of loads slipping from the hook due to vibration, impacts, or other factors. The positive effect of this simple solution, now required by law at construction sites, has been appreciable. A few years ago, serious injuries occurred which were partly caused by the lack of this safety feature.

There are situations in which the usefulness and effectiveness of the latch of the hook are debatable. Sometimes the hook can be detached without any manual operations if it does not have a built-in latch. When the latch is opened, the worker has to walk near the load; sometimes he must climb onto the load to unfasten the hook manually. The risk of slips and falls and the risk of hand injuries increase. This problem has also been illustrated by Firenze (6).

Some types of safety latches have proved to be ineffective at workplaces. The spring which keeps the latch closed wears out in a couple of days. Some safety latches are difficult to use, causing the expenditure of extra time during latching and unlatching operations.

Lifting tackle with several different hooks was constructed so that the span of time used for the attachment of hooks could be studied. Workers at a shipyard fastened and unfastened all the hooks, and the operations were videotaped. The time used for each hook was measured. So far a total of 35 workers have participated in the experiment.

The preliminary results (fig 3) showed that the attachment of a normal lifting hook without a safety latch lasted an average of a couple of seconds. With a simple spring-operated latch it took 1 or $2 \mathrm{~s}$ longer. But for some other types of safety hooks (such as the most durable and reliable ones), the attachment time was $10 \mathrm{~s}$ 
or even longer.

The delay may not be very essential for efficiency at work. But workers who have previously done some simple operations in a couple of seconds are reluctant to accept a new solution which takes more time. The slowest hooks to operate are also the most difficult to attach.

The study will be continued by comparing the technical safety characteristics of the hooks used in the experiment.

\section{Conclusions}

The existing strategies and classifications of safety measures are often biased and do not consider all the factors present when accidents occur. A more comprehensive approach is needed. For occupational accidents, the strategy should comprise at least (i) energy aspects; (ii) aspects of the task and the work, with special consideration being given to irregular operations; (iii) behavioral aspects, including the possibilities of human error; (iv) aspects of the flow of information; and (v) considerations of both the possible chains of events and the relationships between various aspects mentioned.

Adjustment between technical and behavioral approaches is especially inadequate. The lack of knowledge is perhaps not the most essential problem; rather the problem is that the knowledge necessary for prevention is not at the right place at the right time.

In addition to accident analysis, the various techniques for risk analysis, the analysis of human errors, the criticalincident method, the chain-of-event approach, and work analysis should be applied more effectively when existing solutions are evaluated.

Measurements of physiological and psychological quantities, combined with the analysis of technical performance, are needed. The scope of studies should be enlarged so that the studies also cover large-scale prevention systems (eg, safety management, safety inspection, safety information systems, etc).

The following questions are some that must be answered when solutions are evaluated: (i) does the solution really have the intended preventive effect; (ii) do people know the effects of the solution or do they underestimate or overestimate the effects; (iii) what effect does the solution have on the work situation and work performance (delays, new risks, problems, etc); (iv) under which circumstances will the solution be completely accepted and used?

Answers for many of even the simplest solutions implemented at workplaces daily are not available in qualitative or quantitative form.

\section{References}

1. Andersson R, Svanström L. Olycksfall i arbete-analys och åtgärder. Almqvist \& Wicksell AB, Stockholm 1980. 111 p.

2. Burkardt F. Informieren und Motivieren in der Arbeitssicherheit. Glückauf 116 (1980): $16,820-823$.

3. Compes P. Mechanische Sicherungs- uns Schutz-Massnahmen. Symposium für Unfallforshung in Dortmund 1970. Bundesinstitut für Arbeitsschutz, Koblenz 1971, pp 151-190.

4. Concha S. Hazard analysis - Criteria and methods. Hazard prev 17 (1981): Sept/Oct, $6-9$.

5. Ferry TS. Modern accident investigation and analysis - An executive guide. John Wiley \& Sons, New York, NY 1981. 273 p.

6. Firenze $R$. The process of hazard control. Kendall/Hunt, Dubuque, IA 1978. 520 p.

7. Glaister D. Human tolerance to impact acceleration. Injury 9 (1978) $191-198$.

8. Haddon W. On the escape of tigers: An ecologic note. Am j public health 60 (1970) $2229-2234$.

9. Häkkinen K. Safety evaluation of lifting clamps. Prof saf 27 (1982): 5, 24-30.

10. Hale AR, Hale M. A review of the industrial accident research literature. Her Majesty's Stationery Office, London 1972. $96 \mathrm{p}$.

11. Kuhlmann A. Zur Risiko-Akzeptanz in der Technik. Verlag TƯV Rheinland, Köln 1979. $28 \mathrm{p}$.

12. Leplat J. Accident analyses and work analyses. J occup accid 1 (1978): 4, 331340 .

13. Rehtanz H. Perspectives of accident research: Causes and prevention. $J$ occup accid 4 (1982) 121-129.

14. Ross C. Serious injuries are predictable. Prof saf 26 (1981): 12, 22-27.

15. Saari J. Summary of the results of the theme Accidents and Progress of Technology. J occup accid (in press).

16. Schmidt, G. Biomechanische Belastbarkeit menschlicher Körpersteile. Sicherheitsingenieur (1979): 2, 26-31.

17. Skiba R. Die Gefahrenträgertheorie. Bundesanstalt für Arbeitsschutz und Unfallforshung, Dortmund-Marten 1973. 47 p. (Forschungsbericht $\mathrm{Nr} 106$ ).

18. Surry J. Industrial accident research. University of Toronto, Toronto 1969. $203 \mathrm{p}$. 